\title{
基于 EGM2008 模型的区域似大地水准面精化方法分析
}

\author{
许阳阳 任扣清
}

江苏南通市测绘院有限公司

DOI:10.32629/gmsm.v1i4.49

[摘 要] 简要地介绍了 “移去一恢复” 法以及顾及重力场模型的 “移去一恢复” 法的原理。提出在缺少数字高程模型数据的 情况下,利用 EGM2008 地球重力场模型结合 GPS 水准数据确定区域似大地水准面的实施方法, 并结合实例进行计算分析。计 算结果表明: 该方法可以有效提高似大地水准面模型的精度, 使其满足当前城市级似大地水准面的精度要求, 达到区域似大地 水准面精化的目的。

[关键词] 似大地水准面; EGM2008 模型; 移去恢复法; GPS/水准

\section{引言}

当前最严密、最有效的似大地水准面精化方法是利用由 地球重力场模型、地面重力数据和 DEM 数据采用 “移去-恢 复” 法确定重力似大地水准面, 再结合 GPS 水准数据对重力 似大地水准面进行拟合, 进而快速精确地求得与国家或地方 高程系统定义一致的似大地水准面 ${ }^{[1]}$ 。然而这种方法需要的 数据资料不易获取, 且数据处理十分复杂, 适用性不是很广 泛。如果拥有足够高精度的地球重力场模型, 使得地面重力 数据和 DEM 数据的有无对似大地水准面精化的影响较小, 甚 至可以忽略不计, 那么就可以通过顾及重力场模型的 “移去恢复” 法直接拟合似大地水准面 ${ }^{[2]}$ 。本文就复杂地形区域的 实例, 利用 EGM2008 模型, 选取合适的数学拟合模型建立区 域似大地水准面模型, 并通过对比相同方案下 GPS 水准法建 立的似大地水准面模型精度对区域似大地水准面精化进行 可行性分析。

\section{1 原理与方法}

根据地球重力学的理论, 地球表面任意一点的高程异常 可以分解为两个或者三个分量, 即长波分量, 中波分量和短 波分量 ${ }^{[3]}$ :

$$
\zeta=\zeta_{G M}+\zeta_{\Delta G}+\zeta_{T}
$$

式中, $\zeta_{G M}$ 为长波分量, 也称为重力场模型高程异常; $\zeta_{\Delta G}$ 为 中波分量, 也称残差高程异常; $\zeta_{T}$ 为短波分量。如果缺少 DTM 数据, 则可以将高程异常分解为两个部分, 即地球重力场 模型求得的模型高程异常和剩余高程异常 ${ }^{[4]}$ :

$$
\zeta=\zeta_{G M}+\zeta_{C}
$$

式中, $\zeta_{C}$ 表示剩余高程异常, 是将 $\zeta_{\Delta G}$ 和 $\zeta_{T}$ 结合在一 起用一种数学模型逼近的方法来表示。

关于上述高程异常的第二种分解法可以称为顾及重力 场模型的 “移去-恢复” 法。通过寻找合适的数学模型可由 拟合出未知点的剩余高程异常, 再加上重力场模型计算得到 的未知点模型高程异常可以求出未知点的高程异常。“移去-
恢复” 法计算步骤如下 ${ }^{[5]}$ :

(1) 移去: 已知一组 GPS/水准点的高程数据和平面坐标 (或大地坐标), 利用地球重力场模型 EGM2008 求出各已知点 的模型高程异常, 由下式可得到剩余高程异常:

$$
\zeta_{C}=\zeta-\zeta_{G M}
$$

(2) 拟合: 选取合适的数学拟合模型将步骤 (1) 求得的已 知点剩余高程异常 $\zeta_{C}$ 进行拟合, 内插求出待定点的剩余高 程异常。

(3) 恢复: 利用地球重力场模型求出待定点的模型高程 异常, 加上步骤 (2) 求出的剩余高程异常, 得到待定点的高程 异常, 最后求解出待定点的正常高。

\section{2 基于 EGM2008 模型的区域似大地水准面精化算例分析}

2.1 方案设计

山西省某测区 GPS 控制网共有 50 个 GPS 控制点, 控制面积约 为 $3900 \mathrm{~km}^{2}$ 。控制网坐标系为 CGCS2000 大地坐标系, 高程基 准为 1985 国家高程基准, 观测登记三等。

由于测区地势起伏较大, 且控制点位较多 (50 个), 为了 检核各拟合方法的有效性和精度, 在考虑到测区地形地势的 情况下设计了如下表 3.1 共 6 种实验方案。分别利用二次多 项式拟合法、三次多项式拟合法、多面函数法、移动曲面法、

\begin{tabular}{|c|c|c|c|c|}
\hline \multirow{2}{*}{ 方案名 } & \multirow{2}{*}{ 精化方法 } & & 检核 & \multirow{2}{*}{ 拟合点位选取 } \\
\hline & & 点数 & 点数 & \\
\hline 方案一 & 移去恢复法 & 12 & 38 & 选取测区周围分布均匀的 12 个控制点 \\
\hline \multirow{2}{*}{ 方案二 } & \multirow{2}{*}{ 移去恢复法 } & \multirow{2}{*}{15} & \multirow{2}{*}{35} & 在方案一的基础上增加测区内 \\
\hline & & & & 3 个分布均匀的控制点 \\
\hline \multirow{2}{*}{ 方案三 } & \multirow{2}{*}{ 移去恢复法 } & \multirow{2}{*}{20} & \multirow{2}{*}{30} & 分别选取测区四周均匀分布的 15 个控制点 \\
\hline & & & & 和内部均匀分布的 5 个控制点 \\
\hline \multirow{2}{*}{ 方案四 } & \multirow{2}{*}{ 移去恢复法 } & \multirow{2}{*}{25} & \multirow{2}{*}{25} & 在方案三的基础上将测区内部控制点 \\
\hline & & & & 增加至 10 个 \\
\hline \multirow{2}{*}{ 方案五 } & \multirow{2}{*}{ 移去恢复法 } & \multirow{2}{*}{30} & \multirow{2}{*}{20} & 在方案三的基础上将测区内部控制点 \\
\hline & & & & 增加至 15 个 \\
\hline 方案六 & GPS 水准法 & 待定 & 待定 & 选取上述 5 个方案中最优方案的布设点位 \\
\hline
\end{tabular}
移动加权叠加法和移动曲面改进方法等 6 种拟合方法进行 高程异常拟合计算。

表 2.1 实验方案设计 
上述 6 个方案中, 方案一至五是利用基于 EGM2008 模型 的移去恢复法, 其中方案一和方案二作为对比, 检查点位分 布四周和中央的情况下实验模型的精度变化; 而方案三、四、 五作为对比, 检查当外部点位分布一样的情况下随着测区内 部点位个数的增加, 模型精度的变化情况。方案六是利用 GPS 水准法并选取之前 5 个方案中最优点位方案与移去恢复法 中的最优点位方案进行纵向对比分析。

\section{2 模型精度检验}

为了能检验似大地水准面精化的精度, 本文采用模型的 内符合精度、外符合精度来评价实验达到的精度, 经过移去 恢复法的计算步骤得到各方案的内符合精度及外符合精度 对比图表, 见图 2.1、图 2.2。

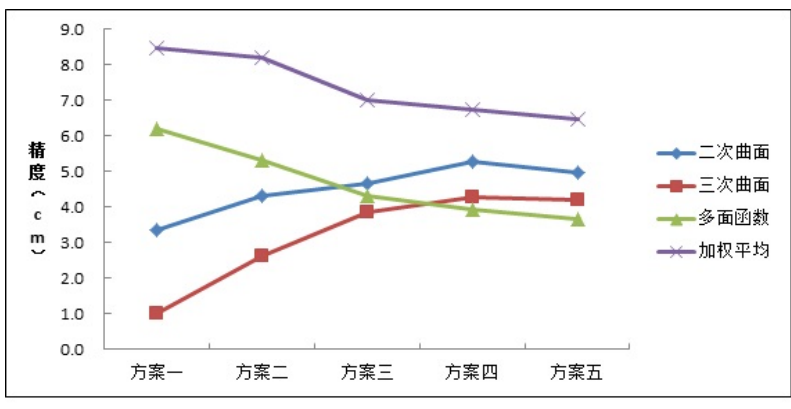

图 2.1 内符合精度对比

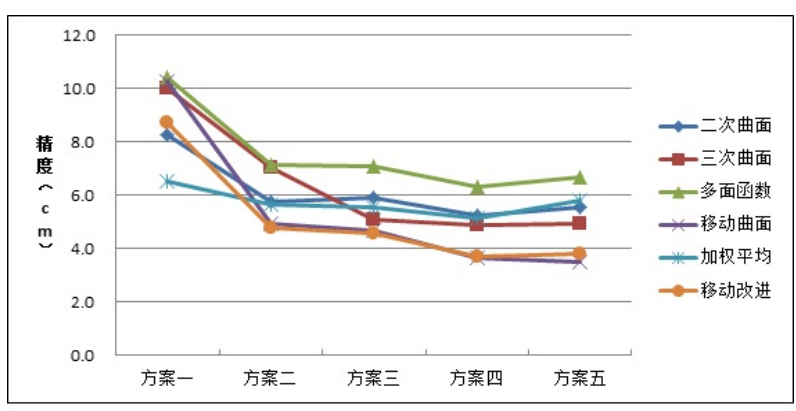

图 2.2 外符合精度对比

由图 2.1 和图 2.2 可以得出结论, 针对测区的具体数据、 地形地貌和已知点分布的情况, 最佳的实验方案是拥有 30 个 拟合点, 且点位布设合理的方案五; 在 6 种拟合模型中, 移动 曲面拟合方法适用性最佳。

最终采用方案五和移动曲面拟合方法计算得到测区未 知点的高程异常, 并与 GPS 水准高程异常进行比较, 残差统 计结果见表 2.2

\begin{tabular}{cccc}
\hline 点数 & 最大绝对值 & 最小绝对值 & 中误差 \\
\hline 20 & 8.36 & 0.12 & 3.53 \\
\hline
\end{tabular}

方案六在上述结论的基础上采用方案五选点方案以及 移动曲面拟合方法, 仅用 GPS 水准数据对测区似大地水准面
进行拟合, 将计算得到的检核点高程异常与实测高程异常进 行比较, 残差统计结果见表 2.3 。

\begin{tabular}{cccc}
\hline 点数 & 最大绝对值 & 最小绝对值 & 中误差 \\
\hline 20 & 28.20 & 0.18 & 8.27 \\
\hline
\end{tabular}

表 2.3 GPS 水准法拟合残差结果统计 (单位: $\mathrm{cm}$ )

由表 2.2 可以看出基于移去恢复法得到的高程异常与 实测高程异常的差值最大绝对值为 $8.36 \mathrm{~cm}$, 最小为绝对值为 $0.12 \mathrm{~cm}$, 中误差为 $3.53 \mathrm{~cm}$ 。而表 2.3 中采用 GPS 水准法得到 的高程异常与实测高程异常的差值最大绝对值为 $28.20 \mathrm{~cm}$, 最小为绝对值为 $0.18 \mathrm{~cm}$, 中误差为 $8.27 \mathrm{~cm}$ 。可以看出, 仅使 用 GPS 水准数据采用最优选点方案及移动曲面拟合方法的 精度可以达到亚米级别, 而使用基于 EGM2008 模型的移去恢 复法的最优方案精度已经达到了厘米级。可以见得, 利用基 于 EGM2008 模型的移去恢复法能有效地提高区域似大地水 准面模型精度, 使其满足当前城市级似大地水准面的精度要 求, 达到区域似大地水准面精化的目的。

\section{3 结束语}

本次实验中, 利用 EGM2008 模型结合 GPS 水准数据, 针对 3900 平方公里测区内的 20-30 个控制点, 采用移去恢复法完 成似大地水准面精化的过程中, 使用计算机的相关软件进行 编程, 可以快速地实现似大地水准面精化, 得到高精度的似 大地水准面模型。在复杂地形的测区, 运用 EGM2008 模型, 结 合 GPS 水准点数据, 采用移去恢复法所获得的似大地水准面 精度比 GPS 水准法要高得多。其中, 利用最优方案和最佳拟 合方法, 区域似大地水准面精化的精度优于 $5 \mathrm{~cm}$, 满足城市级 别的似大地水准面精化对精度的要求。如果再加上前期点位 的合理布设, 在具体的工程项目中可以高效快速且高精度的 完成似大地水准面精化工作。

\section{[参考文献]}

[1]郭春喜,宁津生,陈俊勇,等.珠峰地区似大地水准面精化 与珠峰顶正高的确定 [J].地球物理学报,2008,(01):101-107.

[2]田厚勇. 似大地水准面精化方法研究及在松原灌区中 的应用[D].长春工程学院,2015,(6):77.

[3]李建勋. 基于重力场模型与 GPS 水准组合法区域似大 地水准面精化对比研究[D].长安大学,2015,(2):56.

[4]尤中凯. 基于 GPS/水准数据的局部似大地水准面精化 研究[D].西安科技大学,2016,(05):56.

[5]魏子卿,王刚. 用地球位模型和 GPS 水准数据确定我国 大陆似大地水准面[J].测绘学报,2003,(01):1-5. 